\title{
AVALIAÇÃO COMPARTILHADA ENTRE PROFESSORES FORMADORES E ESTUDANTES DOS CURSOS DE LICENCIATURA
}

\author{
EVALUACIÓN COMPARTIDA ENTRE PROFESORES FORMADORES Y \\ ESTUDIANTES DE LOS CURSOS DE LICENCIATURA
}

\section{EVALUATION SHARED BETWEEN TRAINING TEACHERS AND STUDENTS OF THE LICENSEE COURSES}

\author{
Andressa Graziele BRANDT ${ }^{1}$ \\ Franc-Lane Sousa Carvalho do NASCIMENTO ${ }^{2}$ \\ Nadja Regina Sousa MAGALHÃES ${ }^{3}$
}

RESUMO: No presente trabalho abordamos a importância da avaliação compartilhada entre professor formador e estudantes na formação inicial e no desenvolvimento dos saberes dos futuros docentes, em vista das perspectivas e respostas que o professor retroalimentará suas práticas formativas. Partimos do seguinte questionamento de pesquisa: Como se efetiva a concepção de avaliação como aprendizagem em processos compartilhados de desenvolvimento dos saberes avaliativos nos licenciandos? Deste modo, tecemos como objetivo geral: analisar as experiências compartilhadas de avaliação entre professor formador e licenciandos nos componentes curriculares de História da Educação; Teorias Educacionais e Curriculares e Práticas e Processos Educativos I, ministradas nos cursos de licenciatura em Pedagogia e Matemática do IFC Campus Camboriú. Fundamentamo-nos em autores como: Esteban (2006); Hoffmann (2001, 2003); Libâneo (2012); Lukesi (2006), dentre outros. Essa pesquisa de caráter qualitativo, baseou-se no estudo de caso etnográfico, usamos as técnicas e instrumentos de pesquisa da observação participante e questionário. Percebemos que a avaliação compartilhada é um importante processo de formação dos futuros professores por meio de práticas educativas e pedagógicas dos professores formadores que desenvolvem processos de avaliação como processo de aprendizagem e emancipação dos sujeitos.

${ }^{1}$ Universidade Federal de Santa Catarina (UFSC), Florianópolis - SC - Brasil. Doutoranda do PPGE da na Linha de Pesquisa: Ensino e Formação de Professores. Mestre em Educação pelo Programa de PósGraduação em Educação da. Integrante do grupo de estudos e Pesquisas: Formação de Professores e Práticas de Ensino - FOPPE (UFSC/CNPq) e Integrante do Grupo de Pesquisas Interdisciplinares: Educação, Saúde e Sociedade (UEMA/CNPq). Pedagoga- Supervisora Educacional e Professora da área de Pedagogia do Instituto Federal Catarinense - Campus Camboriú - IFC. E-mail: andressabrandt@hotmail.com; andressa.brandt@ifc.edu.br

${ }^{2}$ Universidade Estadual do Maranhão (UEMA), São Luís - MA - Brasil. Professora da. Integrante do Grupo de Pesquisas Interdisciplinares: Educação, Saúde e Sociedade (UEMA/CNPq). Doutora em Educação pela UFRN. E-mail: franclanecarvalhon@gmail.com

${ }^{3}$ Universidade Federal de Pelotas (UFPEL), Pelotas - RS - Brasil. Doutoranda em Educação pela. Integrante do Grupo de Pesquisas Interdisciplinares: Educação, Saúde e Sociedade (UEMA/CNPq). Email: nadjamagalhaes78@gmail.com 
PALAVRAS-CHAVE: Experiência de avaliação compartilhada. Formação inicial. Processos avaliativos. Auto avaliação. Avaliação como aprendizagem.

RESUMEN: En el presente trabajo abordamos la importancia de la evaluación compartida entre profesor formador y estudiantes en la formación inicial y en el desarrollo de los saberes de los futuros docentes, en vista de las perspectivas y respuestas que el profesor retroalimentará sus prácticas formativas. Partimos del siguiente cuestionamiento de investigación: ¿Cómo se efectúa la concepción de evaluación como aprendizaje en procesos compartidos de desarrollo de los saberes evaluativos en los licenciandos? De este modo, teñimos como objetivo general: analizar las experiencias compartidas de evaluación entre profesor formador y licenciandos en los componentes curriculares de Historia de la Educación; Teorías Educativas y Curriculares y Prácticas y Procesos Educativos I, impartidas en los cursos de licenciatura en Pedagogía y Matemática del IFC Campus Camboriú. Se fundamenta en autores como: Esteban (2006); Hoffmann (2001, 2003); Libneo (2012); Lukesi (2006), entre otros. Esta investigación de carácter cualitativo, se basó en el estudio de caso etnográfico, usamos las técnicas e instrumentos de investigación la observación participante y cuestionario. Se percibe que la evaluación compartida es un importante proceso de formación de los futuros profesores a través de prácticas educativas y pedagógicas de los profesores formadores que desarrollan procesos de evaluación como proceso de aprendizaje y emancipación de los sujetos.

PALABRAS CLAVE: Experiencia de evaluación compartida. Formación inicial. Procesos evaluativos. Auto evaluación. Evaluación como aprendizaje.

ABSTRACT: In the present work we discuss the importance of the shared evaluation between teacher trainer and students in the initial formation and in the development of the knowledge of the future teachers, in view of the perspectives and answers that the teacher will feed back their formative practices. We start from the following research question: How is the conception of evaluation effective as learning in shared processes of development of the evaluation knowledge in the licenciandos? In this way, we have as a general objective: to analyze the shared experiences of evaluation between teacher trainer and licenciandos in the curricular components of History of Education; Educational and Curricular Theories and Practices and Educational Processes I, taught in the undergraduate courses in Pedagogy and Mathematics of IFC Campus Camboriú. We are based on authors such as: Esteban (2006); Hoffmann (2001, 2003); Libâneo (2012); Lukesi (2006), among others. This qualitative research, based on the ethnographic case study, used the techniques and instruments of research to participant observation and questionnaire. We perceive that shared assessment is an important process of training future teachers through the educational and pedagogical practices of teacher educators who develop evaluation processes as a learning process and emancipation of subjects.

KEYWORDS: Shared evaluation experience. Initial formation. Evaluation processes. Self-evaluation. Evaluation as learning. 


\section{Introdução}

Neste estudo, objetiva-se apresentar uma experiência de formação inicial de professores, na qual há a construção e o desenvolvimento dos saberes avaliativos dos futuros docentes pela oportunidade de experimentação de atividades de avaliação compartilhada entre as professoras formadora e os estudantes das Licenciatura em Pedagogia e Licenciatura em Matemática do IFC Campus Camboriú, em quatro componentes curriculares dos referidos cursos, a saber: i) História da Educação; ii) Teorias Educacionais e Curriculares; iii) Pesquisa e Processos Educativos I; e iv) Estágio Supervisionado em Gestão. Componentes curriculares esses ministrados a estudantes dos primeiros e últimos semestres dos referidos cursos. Pretendemos, conforme Ferraço (2012), elucidar nesse texto uma interpretação da teoria por meio da práxis.

As atividades avaliativas tiveram como objetivo realizar uma avaliação colaborativa entre os estudantes e as professoras acerca dos conteúdos desenvolvidos nos componentes curriculares ministrados no primeiro e segundo semestre de 2016 e 2017, por meio de uma avaliação que engloba a dimensão qualitativa e a quantitativa para avaliar a apresentação dos conhecimentos elucidados pelos estudantes e concomitantemente desenvolver os conhecimentos avaliativos e do trabalho docente necessários aos futuros professores.

Assim, o presente texto, expressa uma experiência formativa entre professores formadores e licenciandos, na busca do desenvolvimento dos saberes referentes ao processo avaliativo, em uma tentativa de trazer contributos para o campo da avaliação escolar pela organização de uma prática pedagógica que transversalisa os conhecimentos por meio de um currículo de formação inicial de professor que transcende os conteúdos mínimos de cada componente curricular e que proporciona aos licenciando uma profícua compreensão do processo avaliativo em seus aspectos qualitativos e quantitativos. Nessa perspectiva, concordamos que:

A práxis é uma caminhada de conhecer-se a si mesmo, produto do processo histórico até hoje desenvolvido que deixou marcas, e que só pode iniciar e acontecer na prática, na atividade do dia a dia. Desta forma, uma práxis emancipadora só pode ser construída se a atividade for modificada em sua forma (aparência) e em seu conteúdo (essência). É uma atividade humana, e só neste âmbito se manifesta. (CURADO SILVA, 2011, p. 23). 
Em suma, buscamos no presente estudo a práxis docente, refletir, discutir, interpretar e analisar o conhecimento construído de forma compartilhada entre professores formadores e futuros professores em seu processo inicial de formação, por meio das atividades avaliativa experienciadas nos componentes curriculares do curso de licenciatura.

O presente artigo está organizado em cinco tópicos sendo exposto da seguinte forma: No primeiro trazemos a introdução, expondo as razões e uma apresentação de modo geral que trata a pesquisa; no segundo trataremos a concepção de avaliação e prática avaliativa coletiva; no terceiro tópico abordamos a avaliação compartilhada como processo de formação inicial de professores; no quarto desenvolvemos os percursos metodológicos desenvolvidos; no quinto apresentamos uma experiência de avaliação compartilhada entre professores formadores e futuros professores nos cursos de licenciatura em Pedagogia e Matemática do IFC, abordamos as diversas visões sobre avaliação dando direcionamentos na busca da construção práticas pedagógicas avaliativas para o contexto educativo atual, analisando ainda os aspectos teórico-legais que regem a avaliação educacional no processo ensino aprendizagem.

\section{Avaliação como instrumento de emancipação do sujeito}

A avaliação tem sido vista e praticada no processo de escolarização como conservadora. Nesse entendimento, avaliação vem a ser um grande problema entre professores e alunos porque é utilizada como instrumento de poder do professor para obter disciplina em sala de aula, porém, o objetivo da avaliação é auxiliar o aluno no seu crescimento e na integração consigo mesmo, ajudando-o na apropriação dos conteúdos significativos como: conhecimento, habilidade, hábitos e convicções, (LUCKESI, 2006).

O princípio formativo é o eixo do autodesenvolvimento, estratégia da autonomia, pois ninguém se torna independente no processo de autonomia intelectual sozinho. Esta autonomia surge na interação com o outro sujeito, que em alguns casos são os próprios estudantes. O princípio organizativo é o eixo que acolhe, ensina, confronta o conhecimento do aluno, ajudando-o a organizar-se para ser um cidadão autônomo (LUCKESI, 2006, p. 170). Assim, o processo educativo deve ser sempre planejado e organizado tendo como prioridade o processo de construção do conhecimento. 
A associação entre avaliação formativa e observação necessita estar presente na prática educativa em todos os níveis e modalidades de ensino, de suma importância principalmente nos processos formativos dos futuros professores. Nesse sentido, a avaliação carece estar articulada com processos reflexivos e mediadores junto aos licenciandos, valorizando seu saber, suas potencialidades e possibilidades, de forma a ser formativa e prazerosa, razão pela qual é possível construir a aprendizagem, no lugar de ser apenas autoritária e excludente nos processos de escolarização, seja na educação básica, ou no ensino superior.

De acordo, com o Projeto Pedagógico de Curso de licenciatura em Pedagogia (IFC Camboriú, 2011) e o Projeto Pedagógico de Curso de licenciatura em Matemática (IFC Camboriú, 2010), o processo de avaliação está fundamentado três elementos: a função diagnóstica, a formativa e a somativa. Para Hoffmann (2001), a ação educativa é sempre intencional e o desenvolvimento das atividades educativas pressupõe a avaliação como parte integrante do planejamento do processo de ensino e de aprendizagem. A avaliação cumpre três funções básicas: i) a função diagnóstica: permite verificação dos progressos e dificuldades dos alunos e atuação do professor, que, por sua vez, determinam modificações no processo de ensino; ii) a função formativa: tem por finalidade proporcionar o feedback (retroalimentação) para o professor e para o aluno, durante o desenvolvimento do processo ensino-aprendizagem. Propicia a correção de falhas, esclarecimentos de dúvidas e estímulo à continuidade do trabalho para alcance do objetivo; e iii) a função somativa: tem o propósito de oferecer subsídios para o registro das informações relativas ao desempenho do aluno. Contemplará em seu interior tudo aquilo que foi visualizado na função diagnóstica e formativa.

Em nossas práticas pedagógicas desenvolvidas nos componentes curriculares que ministramos com estudantes das licenciaturas, fundamentamos as avalições desenvolvidas na concepção da avaliação como processo de aprendizagem, a qual se torna realmente democrática quando há a possibilidade de práticas de aprendizagem que permitam o estudante em formação inicial apreender o processo avaliativo pelas experiências proporcionadas em seus próprio processo formativo, proporcionando aos futuros professores a compreensão do processo de aprendizagem por meio da participação ativa nas avaliações das atividades desenvolvidas na sua autoavaliação e avaliação das atividades didáticas e pedagógicas dos professores ministrantes dos 
componentes curriculares que proporcionaram essa experiência avaliativa, tornando-se na nossa perspectiva uma ação educativa e avaliativa significativa aos licenciandos.

Para Luckesi (2002), a avaliação serve para auxiliar cada estudante no seu processo de construção de seus conhecimentos formando para a autonomia e é indicadora de novos rumos. Serve também para compreender o estágio de aprendizagem em que o estudante se encontra, objetivando o avanço no processo da construção de sua emancipação.

Neste sentido, compreendemos que no processo avaliativo democrático, ocorre a construção e o desenvolvimento dos saberes avaliativos pelos futuros professores, pois proporciona a reflexão e questionamentos dos processos e objetivos. Nesta perspectiva, a experiência da participação efetiva dos licenciandos nos processos avaliativos, como sujeitos que realizam e participam da avaliação e não somente são avaliados, isso proporciona a reflexão e análise dos processos avaliativos e sua função como retro alimentador dos processos de ensino e aprendizagem, onde a construção dos processos avaliativos e de seus resultados são realizados de forma compartilhada e colaborativa entre os estudantes do componente curricular e do professor ou professores formadores ministrantes e responsáveis pelo desenvolvimento da profissionalidade docente dos futuros professores.

Tratando-se das bases legais desta pesquisa, vale ressaltar a Lei de Diretrizes e Bases da Educação Nacional que menciona em seu artigo 24, Parágrafo V que a relação ao rendimento escolar observará o seguinte critério: “a avaliação contínua e cumulativa do desempenho do aluno, com prevalência dos aspectos qualitativos sobre os quantitativos e dos resultados ao longo do período sobre os de eventuais provas finais". A lei deixa clara a utilização de dois tipos de avaliação que é a qualitativa e quantitativa. Esta fala que o segundo critério não deve preponderar sobre o primeiro, pois mostra a necessidade de se adotar procedimentos pedagógicos consistentes no processo avaliativo. Nesse sentido, torna-se um grande equívoco avaliar apenas a prova como instrumento final de verificação, pois esta é incapaz de perceber o aluno em sua totalidade, se aprendeu ou não.

A avaliação é um processo que se vale de instrumentos para coleta de dados. Os dados serão úteis se forem pertinentes ao que se pretende analisar e válidos para indicar a continuidade das ações de ensino e aprendizagem. Para tanto os instrumentos devem ser adequados. 
No caso da presente experiência avaliativa, uma avaliação compartilhada de uma metodologia de ensino como um seminário de temas relacionados ao componente curricular, com objetivo e critérios previamente estabelecidos para compor os elementos quantitativos, qualitativos, com problematização, reflexão crítica e autoavaliação dos estudantes e dos professores formadores.

Assim, a avaliação da aprendizagem é uma prática pedagógica útil e necessária para analisar o que se faz. E o papel principal do professor consiste em auxiliar os estudantes a aprender e como avaliar seus futuros alunos, compreendendo que o processo avaliativo fundamentado em uma concepção de ensino e aprendizagem compartilhada torna-se sempre um desafio em função da subjetividade humana na relação com o processo pedagógico e educativo.

\section{O percurso metodológico}

O percurso metodológico de caráter qualitativo se baseou em registro dos instrumentos de avaliação compartilhadas desenvolvidas aulas e trabalhos em forma de seminário das temáticas dos componentes curriculares: História da Educação; Teorias Educacionais e Curriculares; Pesquisa e Processos Educativos I; e Estágio em Gestão.

A partir de uma abordagem etnográfica e dos princípios de estudo de caso, descrevemos, o itinerário percorrido no estudo do contexto sociocultural pesquisado, os cursos de Licenciatura do IFC - Campus Camboriú. Caracterizamos os instrumentos e as técnicas de elaboração de dados, o questionário e análise de conteúdo das respostas dos licenciandos no instrumento de avaliação compartilhada entre os professores formadores e os estudantes, os quais foram utilizados para compreender o processo de descrição do objeto de estudo.

A análise de conteúdo foi utilizada para verificar os sentidos dos interlocutores sobre sua trajetória de formação e a apropriação dos saberes docentes. Segundo Macedo (2006), na análise de conteúdo existem algumas peculiaridades: a primeira trata de um meio para estudar as informações sem restringir ao discurso; a segunda é um conjunto de recursos metodológicos nas análises; e a terceira a inspiração filosófica e teórica que deverá ficar evidente. A análise de conteúdo segue os princípios e algumas, que segundo Bardin (2009) são três: pré-análise; descrição e a interpretação inferencial.

O estudo de caso etnográfico foi utilizado com o objetivo de investigar as contribuições dos processos formativos e do desenvolvimento dos saberes e 
conhecimentos de avaliação escolar, utilizando estratégias pedagógicas de avaliação compartilhada entre professores formadores e futuros professores.

O estudo de caso possui tradição na pesquisa científica como um estudo descritivo para fins de tratamento e intervenção na realidade. Na compreensão de André (1995), o estudo de caso etnográfico surgiu mais recentemente, como uma concepção específica de estudo, dentro da abordagem interpretativa na perspectiva etnográfica de pesquisa.

Nesse estudo, elegemos como interlocutores; 02 (dois) professores formadores, selecionados através dos seguintes critérios: ser professor dos cursos de licenciatura e partilhar com os estudantes de estratégias de avaliação compartilhadas com os licenciandos. E quatro (quatro) estudantes; sendo 2 (dois) da licenciatura em Pedagogia e 2 ( dois) da licenciatura em Matemática, selecionados através dos seguintes critérios: ter participado do seminário que envolveu a proposta pedagógica da avaliação compartilhada, ter respondido as questões referentes a sua auto avaliação qualitativa e quantitativa em relação à sua participação no seminário do componente curricular e ter respondido a avaliação referente aos processos didáticos e pedagógicos desenvolvidos pelo professor formador no decorrer do semestre letivo.

O questionário com questões abertas e fechadas foi um recurso ou técnica de coleta de dados, utilizada com os licenciandos do IFC - Campus Camboriú, que participaram dos seminários e dos quatro componentes curriculares em que foram desenvolvidas práticas pedagógicas avaliativa em colaboração com os futuros professores.

\section{O processo pedagógico por meio da experiência da avaliação compartilhada}

Segundo Pimenta (2010), no levantamento das produções acadêmicas das pesquisas em Didática no âmbito do GT da ANPEd dos últimos anos, possibilita concluir que, em sua maioria, as pesquisas destacam a análise de situações que analisam a prática e os contextos escolares, compreendendo o objeto de estudo da Didática, como fenômeno social, concreto, complexo e multirreferencial e, consequentemente a realização de pesquisas sobre as experiências práticas de professores e sobre os contextos escolares considerados em suas múltiplas determinações.

Nesse sentido, nos interessa uma análise e discussão das experiências práticas pedagógicas concretas vivenciadas pelos professores formadores e licenciandos nos 
componentes curriculares de dois cursos de licenciatura. Concordamos, que:

[...] ao defendemos a necessidade de problematizarmos os modos como cada um de nós vê, entende, trabalha, fala sobre ou se relaciona com os currículos, as didáticas, as avaliações, os planejamentos, enfim, com os múltiplos processos educacionais tecidos nas redes de conhecimentos partilhadas nos cotidianos escolares, vamos, aos poucos, nos dando conta das possíveis contribuições das pesquisas nos dos com os cotidianos para esse debate, [...]. (FERRAÇO, 2012, p. 116).

Nesse sentido, observamos que o ato avaliativo requer uma análise que possibilite estudar o fenômeno avaliação, a partir de princípios que melhor explicitem seu sentido e o seu significado no processo de formação do ser humano, no sentido de favorecer a ligação dos saberes: conhecer, sentir e agir. No entanto, a prática avaliativa utilizada pelos professores no cotidiano escolar, ainda é vista como um componente causador de muitas insatisfações, inquietudes e vastas interpretações.

Percebemos ainda que a prática avaliativa que temos atualmente no contexto educativo continua a classificar, comparar, escalonar, aprovar, reprovar, formalizar, linearizar, reduzir, isolar, quantificar e fragmentar o conhecimento do aluno, não leva em conta o seu potencial criativo, experiência de vida e o quando possa vir a aprender no processo de formação e construção do conhecimento (LUCKESI, 2006).

O professor é aquele que acolhe o estudante do jeito que ele é, e ajuda na construção do conhecimento, saber, experiência e o afeto. Do ponto de vista de Luckesi (2006), a avaliação confronta os saberes do aluno para diagnosticar o que está ocorrendo no processo de desenvolvimento da sua formação, sinalizando dialogicamente outras possibilidades. Pois, a avaliação diagnostica para reorientar, mas, lamentavelmente, o reflexo da prática avaliativa utilizada na escola é a reprovação do aluno que é aceita em nossa sociedade como um processo natural e obrigatório, explicitando que a repetência é o meio de preservação da qualidade do ensino e a evasão, o rumo natural dos que fracassam.

As práticas avaliativas docentes devem primar pelo desenvolvimento dos sujeitos por meio do processo de ensino-aprendizagem. Ao fazer isso, o professor não somente estará averiguando o quanto o aluno aprendeu ou não em cada contexto que se propõe a avaliar, mas estará, acima de tudo, valorizando o que o aluno sabe e possibilitando processos de reflexão sobre o que pode ou poderá aprender diante do seu esforço e do seu saber elaborado, e não descartando-os como muitas práticas acabam, grosseiramente, fazendo. Dessa forma: 
O professor, ao utilizar a avaliação como um recurso para o educando verificar seu crescimento, estará permitindo o aluno a se tornar um aprendiz crítico capaz de avaliar as contribuições feitas pelos outros; estará oportunizando ao aluno conhecimentos relevantes para a solução de problemas; estará oferecendo condições para o aluno ser criativo e livre, além de capaz em suas iniciativas e responsável por suas ações (SANT'ANNA, 2009, p. 43).

Para que isso aconteça, o professor precisa ressignificar suas práticas e reflexões acerca da avaliação, uma vez que no próprio processo formativo, somos imbuídos de práticas conservadoras e repetitivas. Tal superação exige mais do que a compreensão dos processos avaliativos à luz de uma teoria e epistemologia da área, significa repensar esses condicionantes articulando com o próprio cotidiano dos educandos, que levam para a escola saberes, discussões e práticas outras que extrapolam o que a escola pratica e pensa, e estas não podem ser tratadas como erros ou que não se adéquam ao ambiente escolar, mas, pelo contrário, deve-se promover essas aprendizagens.

Portanto, uma avaliação contínua justifica-se no fato de que as observações das aprendizagens dos estudantes não devem se realizar apenas em tempos fixados pela escola e professores, pois, entendemos que os estudantes aprendem de variadas formas, em tempos nem sempre homogêneos. Portanto, torna-se necessário planejar e organizar a prática escolar, para viabilizar uma avaliação que possa atender as diferenças de aprendizagens de cada aluno, “[...] pois avaliar para promover, significa compreender a finalidade dessa prática a serviço da aprendizagem, da melhoria da ação pedagógica, visando a promoção moral e intelectual dos alunos" (HOFFMANN, 2003, p. 18).

Concordamos que a avaliação poderá ser emancipatória, no sentido de superar a cultura clássica que o saber impõe na escola. Ou seja:

A avaliação como relação reflexiva e dialógica, vinculada à dinâmica de emancipação social, demanda ruptura com um modelo de avaliação constituído na lógica da subordinação do sujeito que não sabe, em nosso caso o estudante, a quem sabe, figura na escola representada pelo professor ou professora (ESTEBAN, 2006, p. 88).

Com essa perspectiva da avaliação, é possível estimular a criatividade no cotidiano da escola e acima de tudo tornar as relações prazerosas e instigantes no processo de ensino.

\section{A experiência de práticas formativas e de avaliação dos professores formadores nas licenciaturas}


As professoras formadoras utilizaram como instrumento de avaliação compartilhada, seminários desenvolvidos nos componentes curriculares ministrados por elas, questões com perguntas abertas e fechadas relacionas ao conteúdo do seminário, elaboração de questão problematizadora para os grupos, autoavaliação da sua participação na elaboração e apresentação do seminário e uma nota quantitativa, avaliação do componente curricular e consequentemente das professoras formadoras. Conforme segue o exemplo abaixo:

\section{AVALIAÇÃO DO SEMINÁRIO:}

Objetivo: Realizar uma avaliação colaborativa entre estudantes e a professora acerca das temáticas estudadas, por meio de uma avaliação que engloba a dimensão qualitativa e a quantitativa para avaliar a apresentação dos conhecimentos elucidados pelos estudantes.

\section{1-AVALIAÇÃO DOS GRUPOS:}

Grupo 01:

Data:

a) O grupo apresentou as principais ideias da temática em relação a educação, sociedade, marginalidade, escola, professor, aluno, avaliação, processo de ensino e aprendizagem, proposta pedagógica?

( ) Sim ( ) Não ( ) Parcialmente

\section{b) Apresentação oral do trabalho}

Nota $(0$ a 10)

Domínio do conteúdo do trabalho apresentado. Nota:

Clareza e objetividade na comunicação. Nota:

Postura/comportamento durante a $\overline{\text { apresentação. Nota: }}$

Uso adequado do tempo (20 minutos). Nota:

Total das notas:

c) Elabore um questionamento para o grupo:

\section{2-AUTOAVALIAÇÃO DA PARTICIPAÇÃO NOS SEMINÁRIOS:}

a) Descreva como foi sua participação na realização das atividades do grupo para a elaboração e apresentação do seminário:

b) Escreva como você se sentiu realizando essa atividade de elaboração, apresentação e avaliação dos grupos nos seminários:

c) Nota para o seu desempenho nos seminários de 0-10:

\section{3-AVALIAÇÃO DO COMPONENTE CURRICULAR:}

a) Escreva como você avalia o desenvolvimento dos conteúdos e as aprendizagens nas aulas desse componente curricular.

b) Na avaliação do componente curricular, considere a importância do mesmo, na sua formação como professor(a) e escreva sua avaliação em relação: as estratégias pedagógicas e didáticas da professora ministrante, seu empenho na preparação e desenvolvimento das aulas, a sua assiduidade e pontualidade, bem como o alcance dos objetivos traçados no Plano de Ensino. 
Na nossa compreensão, como professoras formadoras, a realização da avaliação compartilhada possibilitou aos professores formadores uma experiência pedagógica que lhes forneceu informações acerca da sua atuação na aprendizagem dos licenciandos, mostrando a trajetória formativa no contexto educativo pelos mesmos. Portanto, buscamos reconceptualizar o campo da avaliação, desmitificar e abandonar as perspectivas técnicas e quantitativas para assim criar conceitos e visões em um sentido emancipatório e formativo no processo de desenvolvimento do ser humano.

Nessa perspectiva, quando um professor utiliza meios avaliativos e práticas participativas, formativas, compartilhadas e significativas constantemente, estará conquistando um respeito, o afeto e elevando a autoestima dos alunos. Facilita também a aprendizagem ao torná-la mais prazerosa através de um ambiente propício para tal. Com essa postura o professor estará mudando a sua concepção sobre como utilizar os instrumentos de avaliação e ressignificando o ato de avaliar, contribuindo assim, na melhoria da qualidade do ensino e em especial no processo educacional de formação do aluno.

A avaliação é parte integrante do processo de ensino e aprendizado, e o meio do qual o professor utiliza-se para obter informações sobre os rendimentos e aprendizagem dos alunos, e visualizar dificuldades pessoais dos mesmos e também aperfeiçoar e redirecionar o seu trabalho tendo em vista uma prática educativa transformadora.

\section{A percepção dos licenciandos referente a constituição dos saberes avaliativos por meio de experiências vivenciadas}

Para Franco (2012), “[...] transformar teorias em práticas não é algo simples nem algo que dependa apenas da boa formação de mestres. Essa transposição implica adesão, contrato social, desejo coletivo da sociedade, condições institucionais de trabalho, empenho político. "'(p. 56). Será importante, portanto, que, durante uma pesquisa-ação, haja tempo e espaço para cada sujeito ir apropriando-se das mudanças operadas em suas significações de mundo, que implicam, essencialmente, mudanças em si próprio como sujeito.

Nas respostas dos licenciandos de Pedagogia e da Matemática, passamos a analisar o posicionamento dos interlocutores em relação as questões de autoavaliação dos seminários:

RPGE- Revista on line de Política e Gestão Educacional, Araraquara, v. 22, n. 2, p. 507-523, maio/ago., 2018. ISSN: 1519-9029. 
EP1 - [...] e relação a elaboração da atividade do seminário, foi muito bom, pois todas nós nos envolvemos na elaboração, discussões e na elaboração de dinâmica das apresentações. A apresentação ocorreu conforme o nosso planejamento e foi bem rica, pois proporcionou discussões que se enquadravam nos conceitos apresentados. No que tange a avaliação, foi um tanto desconfortável, pois o processo avaliativo é complexo e envolve dimensões que vão além da explanação de conteúdo [...].

EP2 - Na questão da elaboração e apresentação foi uma aprendizagem e os grupos trabalharam de forma dinâmica. Em relação a avaliar os colegas dos grupos, foi difícil, mas aos poucos vamos aprendendo.

EM3 - [...] Foi um trabalho muito importante, que serviu como base para ensinar as matérias uns aos outros e sermos bem aceitos e compreendidos [...]. Em relação a avaliação dos colegas e de seus grupos, me senti confortável, pois a vida é avaliar e ser avaliado, tendo a humildade de aceitar e crescer com os críticos.

EM4 - O trabalho dos seminários foi muito significativo, pois eu não tinha conhecimento sobre o tema trabalhado e com certeza será mais significativo futuramente quando eu colocá-lo em prática. Trabalhamos de forma coletiva no nosso grupo e dividimos algumas atribuições, como fazer os slides e partes da apresentação. A apresentação poderia ser melhor se não houvesse tanto nervosismo. A ideia de poder avaliar os outros grupos foi muito boa, além de conhecer muita coisa do conteúdo da disciplina, nos "prepara" para avaliar nossos futuros alunos.

A compreensão dos interlocutores, traz dois posicionamentos distintos, os dois estudantes do $8^{\circ}$ semestre do curso de Licenciatura em Pedagogia consideraram a atividade compartilhada de avaliação significativa, porém se sentiram desconfortáveis em avaliar os colegas de curso.

Nesse sentido, para Luckesi (2006), a prática da avaliação da aprendizagem apresenta-se, muitas vezes, como um ato ameaçador, autoritário e seletivo, confirmando um processo de exclusão. $\mathrm{O}$ ato de avaliar não deve se resumir a instrumentos de provas/exames; estes objetivam apenas verificar o nível do desempenho do educando em determinado conteúdo, classificando-o como aprovado ou reprovado. Uma das principais finalidades da avaliação escolar deve ser a de proporcionar resultados para a reflexão da prática pedagógica dos professores e alunos.

Isto nos permite refletir em torno da avaliação no ambiente escolar, da sua organização e do papel de gestores, professores e alunos, ou seja, uma nova maneira de pensar a escola e sobretudo, a prática pedagógica dos que atuam na profissão de educador. Segundo Alarcão (2001), nessa escola acreditamos que formar, é organizar 
contextos de aprendizagem exigentes e estimulantes; ambientes formativos que favoreçam o cultivo de atitudes saudáveis e o desabrochar das capacidades de cada um, com vistas ao desenvolvimento de competências que lhe permitam viver em sociedade.

Estas dificuldades manifestadas por aqueles que vivenciam a avaliação residem no fato de que, existe um distanciamento entre o conhecimento dos princípios teóricos (saber) e a prática (fazer). Então, os saberes adquiridos pelo professor durante a formação inicial e continuada não estão sendo postas em prática no contexto escolar, pois o discurso é que avaliar ainda é medir conhecimento, por mais que se mencione no âmbito educativo que a avaliação seja contínua e significativa não medindo apenas o que o aluno domina de conteúdo que lhe foi ensinado, mas também habilidades que vão do conhecimento para a interpretação desse conteúdo e a capacidade de aplicá-lo no seu cotidiano, isto é, ao longo da vida.

Os estudantes do primeiro semestre do curso de Licenciatura em Matemática, avaliaram como de suma importância a avaliação e realização dos seminários para o desenvolvimento de seus conhecimentos e de suas práticas pedagógica e avaliativas, considerando o processo de experimentação da avaliação dos grupos como algo necessário na realidade educacional, os mesmos estudantes, consideraram a ideia de avaliar os colegas como uma oportunidade de desenvolvimento dos saberes avaliativos, ou seja, importante para aprender a avaliar os seus futuros alunos.

Nessa perspectiva, avaliação como contínua e significativa, existe o foco de fornecer informações acerca das ações de aprendizagem dos educandos, mostrando cada passo percorrido pelo aluno e quais entraves o impedem de progredir na busca da melhoria do processo de aprendizagem, buscando então um processo emancipatório em busca de melhores compreensões e soluções para os seus próprios conflitos de aprendizagem. Portanto, a avaliação não pode apenas ser realizada no final de uma etapa, sob a pena de perder o seu propósito. Ao avaliar, o professor estará constatando as condições de aprendizagem dos alunos, para reorganizar os meios e formas para sua recuperação e reestruturação, e não para sua exclusão, se considerar a avaliação como um processo contínuo e formativo.

A avaliação da aprendizagem deverá ser assumida como um componente de compreensão do estágio de aprendizagem que se encontra o aluno. Segundo Luckesi (2006), a avaliação deve ter como objetivo tomar decisões suficientes e satisfatórias para que se possa avançar no processo de aprendizagem. Por isso, as relações professoraluno devem ser dialógicas e dinâmicas, destituindo a figura de que "quem sabe é quem 
domina”. Superar esse posicionamento, talvez seja um dos maiores desafios que enfrentamos hoje na escola em busca de uma educação mais justa, democrática e igualitária.

\section{Considerações finais}

O professor, ao realizar uma experiência formativa que busque desenvolver nos licenciandos os saberes avaliativos para futuros professores, precisa ter fundamentação teórica para o desenvolvimento de suas estratégias de ensino e aprendizagem, o que acontece nos ambientes educacionais.

Contudo, ao realizar com os estudantes a avaliação compartilhada, o professor formador poderá considerar não somente o momento em que utilizou algum instrumento avaliativo qualitativo e quantitativo, mas considerar o percurso de aprendizagem dos estudantes, diante de perspectivas analíticas, que o fazem um ser singular, e com características heterogêneas, levando ainda, em consideração, que cada aluno reage de uma maneira diferente ao participar de um momento avaliativo que o professor está utilizando, modificando comportamentos e situações dos futuros professores.

Para Franco (2012), para a análise e avaliação das práticas, será necessário um trabalho contínuo, em que professores e estudantes se envolvam na auto-observação e na observação de outros, refletindo sobre as transformações na realidade que as ações práticas produzem, reconstruindo suas percepções, construindo novas teorias sobre as práticas avaliativas, trocando e analisando intersubjetivamente suas compreensões.

Assim, compreendemos que a avaliação compartilhada fortalece o processo pedagógico avaliativo dos componentes curriculares, que trabalham com a proposta didática da avaliação compartilhada entre professores formadores e os futuros professores, estudantes dos cursos de licenciatura, pois ensinar os conhecimentos da avaliação escolar, busca o desenvolvimento de saberes específicos, que envolvem a prática, as experiências, a teoria, a pesquisa e principalmente a emancipação crítica dos sujeitos, e o entendimento dos licenciandos que no exercício de sua futura prática docente, é fundamental saber as razões pelas quais ensina e avalia através da perspectiva da avaliação da aprendizagem.

AGRADECIMENTOS: IFC Campus Camboriú. 


\section{REFERÊNCIAS}

ALARCÃO, Isabel. Escola reflexiva e nova racionalidade. Porto Alegre: Artmed. 2001.

BARDIN, Laurence. Análise de Conteúdo. Lisboa, PT: 70, 2009.

CURADO SILVA, Kátia Augusta Pinheiro Cordeiro. A Formação de Professores na Perspectiva Crítico-emancipadora. Linhas Críticas, Brasília, DF, v. 17, n. 32. p. 13-31, 2011.

ESTEBAN, Maria Tereza. Avaliação: uma prática em busca de novos sentidos. 2.ed. Coleção O sentido da Escola: Ed. DP\&A. Rio de Janeiro, 2000.

ESTEBAN, Maria Tereza. Avaliação numa perspectiva emancipatória: desafio cotidiano às práticas escolares. In: GARCIA, Regina Leite.; ZACCUR, Edwiges. Cotidiano e diferentes saberes. Rio de Janeiro: DP\&A, 2006.

FERRAÇO, Carlos Eduardo. Possíveis Tessituras entre currículo e didática: sobre conhecimentos, experiências e problematizações. In: LIBÂNEO, José Carlos.; ALVES, Nilda (Org.). Temas da Pedagogia: diálogos entre didática e currículo. São Paulo: Cortez, 2012, p. 98-123.

FRANCO, Maria Amélia do Rosário Santoro. Pedagogia e prática docente. 1 ed. São Paulo: Cortez, 2012.

HOFFMANN, Jussara Maria Lerch. Avaliar para promover: as setas do caminho. Porto Alegre: Mediação, 2001.

HOFFMANN, Jussara Maria Lerch. Avaliação: mito e desafio: uma perspectiva construtivista. 32.ed. Porto Alegre: Mediação, 2003.

LIBÂNEO, José Carlos; ALVES, Nilda (Org.). Temas da Pedagogia: diálogos entre didática e currículo. São Paulo: Cortez, 2012.

LUCKESI, Cipriano Carlos. Avaliação da aprendizagem escolar: estudos e proposições. 18.ed. São Paulo: Cortez, 2006.

PIMENTA, Sema Garrido. Epistemologia da prática e ressignificando a Didática. In: PIMENTA, Sema Garrido; FRANCO, Maria Amélia Santoro (Org.). Didática: embates contemporâneos. São Paulo: Loyola, 2010, p. 15-41.

PIMENTA, Sema Garrido. Professor reflexivo: construindo uma crítica. In: PIMENTA, Sema Garrido; GUEDIN, Evandro. (Orgs.). Professor reflexivo no Brasil: gênese e crítica de um conceito. 3 ed. São Paulo: Cortez, 2005.

SANT'ANNA, Ilza Martins. Porque avaliar? como avaliar? critérios e instrumentos. 13 ed. Petróplis, RJ: Vozes, 2009.

SANTOS, Francesca Danielle G. dos.; CIASCA, Maria Isabel F. Lima. Avaliando o projeto "primeiro, aprender": origem, implementação e percepção. In: VIANA, Tânia 
Vicente.; CIASCA, Maria Isabel Figueiras Lima.; SOBRAL, Adriana Eeufrásio Braga (Orgs.). Múltiplas dimensões em avaliação educacional. 1 ed. Fortaleza: Imprece editorial, 2010.

\section{Como referenciar este artigo}

BRANDT, Andressa Graziele.; NASCIMENTO, Franc-Lane Sousa Carvalho do.; MAGALHÃES, Nadja Regina Sousa. Avaliação compatilhada entre professores formadores e estudantes dos cursos de licenciatura. Revista on line de Política e Gestão Educacional, Araraquara, v. 22, n. 2, p. 507-523, maio/ago., 2018. ISSN: 15199029. DOI: 10.22633/rpge.v22.n2.maio/ago.2018.11194

Submetido em: 14/03/2018

Aprovado em: 26/06/2018 